\title{
Water vapor conductance: a technique using eggshell fragments and relations with other parameters of eggshell
}

\author{
Itallo Conrado Sousa de Araújo ${ }^{1 *}$, Nadja Susana Mogyca Leandro', Mariana Alves Mesquita1, \\ Marcos Barcellos Café1, Heloisa Helena Carvalho Mello' ${ }^{1}$, Elisabeth Gonzales ${ }^{1}$
}

${ }^{1}$ Universidade Federal de Goiás, Departamento de Zootecnia, Goiânia, GO, Brazil.

\begin{abstract}
The objective of this study was to evaluate a technique for quantifying eggshell conductance using shell fragments from hatched eggs. Additional objectives were to calculate the correlation between eggshell conductance, porosity, and thickness and correlate these parameters with incubation data. The study design was fully randomized in a $3 \times 3$ factorial scheme (three egg regions - large end, equator, and narrow end - and three ages of broiler breeders - 29, 35, and 59 weeks). A total of 216 eggs were used, with 24 repetitions for each treatment. Neither conductance nor shell thickness showed any interaction with egg region. Breeder age influenced eggshell conductance, such that it was greatest in eggshells from 59-week breeders $\left(0.323 \mathrm{mg} \mathrm{day}^{-1}\right.$ torr $\left.^{-1}\right)$, while for 29 -week and 35 -week breeders, the conductance values found were 0.285 and $0.270 \mathrm{mg} \mathrm{day}^{-1}$ torr $^{-1}$, respectively. The eggshell thickness was similar in eggs from 29 and 35 -week breeders and these were greater than the thickness of eggshells from 59-week breeders. Correlations between mean eggshell conductance and chick body weight and yolk free chick body weight were found significant. There were no correlations between mean eggshell thickness and any of the data evaluated. There were positive correlations between mean eggshell porosity and egg weight loss up to the time of transfer, chick weight, and yolk free body weight. The technique of using eggshell fragments can be used for measuring eggshell conductance. Eggshell porosity is the characteristic that best correlates with incubation parameters.
\end{abstract}

Key Words: fertile eggs, porosity, shell conductance, shell thickness

\section{Introduction}

Eggs are a system that supports embryo development provided that warmth, humidity, periodic turning, and gas exchange are available. The embryo development rate is directly dependent on the oxygen supply that is diffused through the pores of the shell. According to Ar et al. (1974), conductance is the capacity to achieve gas exchanges (oxygen, carbon dioxide, and metabolic water), which take place in eggs through the pores in their shells. Thus, the biological concept of shell conductance is based on the fact that the quantity of energy available for embryo development depends on the quantity of oxygen that enters the egg through its shell, given that embryo metabolism is primarily aerobic.

Received: May 28, 2017

Accepted: August 9, 2017

*Corresponding author: italloconradovet@hotmail.com

http://dx.doi.org/10.1590/S1806-92902017001200004

How to cite: Araújo, I. C. S.; Leandro, N. S. M.; Mesquita, M. A.; Café, M. B.; Mello, H. H. C. and Gonzales, E. 2017. Water vapor conductance: a technique using eggshell fragments and relations with other parameters of eggshell. Revista Brasileira de Zootecnia 46(12):896-902

Copyright (C) 2017 Sociedade Brasileira de Zootecnia. This is an Open Access article distributed under the terms of the Creative Commons Attribution License (http://creativecommons.org/licenses/by/4.0/), which permits unrestricted use, distribution, and reproduction in any medium, provided the original work is properly cited.
Eggshell conductance is related to loss of metabolic water and gases from inside the egg to the external environment. During the incubation period, it is important to maintain the rate of water loss at an appropriate level for satisfactory hatching, i.e., between 10 and 14\% (Araújo et al., 2016). According to Gonzales and Mello (2012), problems of inappropriate egg weight loss due to low or high conductance can be corrected within certain limits, through increasing or decreasing the humidity within the incubation environment. However, eggshell conductance is still subject to change over the course of the incubation period, relating to genetics, age and diet of breeders, egg weight at the start of incubation, embryo size, eggshell quality, and the temperature and humidity of the incubation environment.

In commercial incubators, measurement of egg weight loss from the start of the incubation process to the time of egg transfer from the incubation machine to the hatcher is an indirect means of obtaining eggshell conductance values and, thus, ascertains whether adequate gas exchange is occurring (Shafey, 2002). Proper management of humidity during incubation based on knowledge of eggshell conductance may result in better hatchability, birth window, and chick quality. Therefore, knowledge of conductance values, as a characteristic of eggshells, is of great importance for making better use of incubation parameters. 
The technique currently used for quantifying eggshell conductance was proposed experimentally by $\mathrm{Ar}$ et al. (1974), who used the entire egg. The egg is placed in a desiccator made of glass, containing silica gel to ensure that there is no humidity in the environment and the temperature is controlled at $25{ }^{\circ} \mathrm{C}$. Considering that the internal environment of the egg is saturated, water loss through the shell pores occurs because of the pressure difference between inside and outside the egg; eggshell conductance measurements can thus be obtained. However, this technique does not allow evaluation of eggshell conductance as the embryo develops. The conductance may vary as a function of the absorption and use of the residual yolk, conditioned through gas exchange consisting of entry of oxygen and exit of carbon dioxide and metabolic water that the embryo itself produces.

Portugal et al. (2010) developed a technique for obtaining eggshell conductance that used eggshell fragments from extinct. The technique used was validated experimentally by these authors and they found that the conductance obtained through their proposed method was compatible with the results from the traditional method (using whole eggs) that had been presented by Ar et al. (1974).

Evaluation of eggshell conductance after hatching may constitute a simple and routine field practice. Data on each batch, age, and lineage that are stored in a database may enable quick decisions regarding adjustments to temperature and humidity in the incubation machine. This would optimize the incubation process in different types of incubator, which could be single- or multiplestage. However, no methods for evaluating the eggshell conductance of broiler chickens using only fragments of the shells have been reported in the literature.

Therefore, the objective was to evaluate a technique for quantifying eggshell conductance using only eggshell fragments. This study also aimed to investigate correlations between eggshell conductance and eggshell quality (thickness and porosity) and between conductance and incubation parameters.

\section{Material and Methods}

This experiment was conducted at a university in the city of Goiânia, GO, Brazil and at a commercial incubator in the city of Itaberaí, GO, Brazil (Latitude: $16^{\circ} 01^{\prime} 13^{\prime \prime} \mathrm{S}$ and Longitude: $49^{\circ} 48^{\prime} 37^{\prime \prime}$ W). Research on animals was conducted according to the institutional committee on animal use (case no. 038/2013).

The treatments involved a combination of two factors: ages of breeders and the region of the eggshell. Broiler breeders of the commercial lineage Cobb500 of three different ages $(29,35$, and 59 weeks) were used and three eggshell regions (large end, equator, and narrow end) were examined, thus totaling nine treatments. The study design was fully randomized in a $3 \times 3$ factorial scheme (breeder age versus eggshell region) and the experimental unit was one egg. There were 24 repetitions per treatment, thus totaling 216 eggs. The eggs of 29-week-old breeders weighed $59.16 \pm 1.25 \mathrm{~g}$, of 35 -week-old breeders, $60.02 \pm 1.01 \mathrm{~g}$, and of 59 -week-old breeders, $69.70 \pm 1.09 \mathrm{~g}$.

Shells were obtained from recently hatched eggs from broiler breeders of the Cobb500 strain, of different ages. The eggs had all been incubated in one single-stage commercial machine, distributed in four central trays of the cart of incubation, with each tray containing eggs of all the ages of the breeders. Before the experiment was conducted on the shells, the physical quality of the neonate chicks from each of the 216 eggs studied was analyzed. This was noted for subsequent correlation with the shell quality data. The following parameters were evaluated: egg weight loss from the start of incubation to the time of transfer (18 days), egg weight loss from one day until 18 days, chicken body weight, percentage of chicken body weight (chick body weight $\times 100$ /egg weight), residual yolk weight, percentage of residual yolk weight (residual yolk weight $\times 100 /$ egg weight), yolk free body weight, and percentage of yolk free body weight (yolk free body weight $\times 100 /$ egg weight).

The technique used to determine the conductance was adapted from Portugal et al. (2010), who also used shell fragments from recently hatched eggs. In this trial, plastic microtubes with a capacity for $1.5 \mathrm{~mL}$ of water were used.

The shells were washed in distilled water and the shell membranes were removed with the aid of tweezers and a sponge. The shells were left to dry for $2 \mathrm{~h}$ at room temperature. Subsequently, fragments of approximate size of $2 \mathrm{~cm}^{2}$ were cut, such that they would be big enough to cover the entire opening of the plastic microtube (Figure 1). Each region of the egg was evaluated (narrow end, equator, and air chamber). Two repetitions were used per region, thus totaling six shell fragments from each egg.

One thousand and two hundred sixty plastic microtubes, each with a capacity of $1.5 \mathrm{~mL}$, were used. The microtubes were each labeled and filled with $1.0 \mathrm{~mL}$ of distilled water. Then, the eggshell fragment was glued across the opening of the microtube using plastic glue applied to the rim of the microtube. Mild pressure was used to ensure adhesion between the shell and the rim, while avoiding entry of the glue into the microtube. The microtubes were held vertically in a Styrofoam plate and were left at room temperature $\left(25^{\circ} \mathrm{C}\right.$ ) for $2 \mathrm{~h}$ for the glue to dry. After this drying 
period, the microtubes were weighed for the first time. They were then placed in two desiccators $(305 \times 305 \times 305$ $\mathrm{mm}$, with a volume de $24.6 \mathrm{~L}$ ), such that each desiccator contained 630 shell fragments. The desiccators contained desiccating silica (blue silica gel), which provided an internal environment with zero humidity.

Eggshell conductance was determined directly from the weight loss of the plastic microtube during the period for which it was kept inside the desiccator. Thus, the microtubes were weighed on four consecutive days, at 24-h intervals. This was done with a balance with precision to four decimal places (OHAUS Adventurer).

The weight loss was used to calculate the specific conductance of the shell (narrow end, equator, and large end) and mean conductance. The formula proposed by Portugal et al. (2010) was used:

$$
\mathrm{G}_{\mathrm{H} 2 \mathrm{O}}=\frac{\mathrm{M}_{\mathrm{H} 2 \mathrm{O}}}{\Delta \mathrm{P}_{\mathrm{H} 2 \mathrm{O}}},
$$

in which $\mathrm{G}_{\mathrm{H} 2 \mathrm{O}}\left(\mathrm{mg} \mathrm{day}^{-1}\right.$ torr $\left.^{-1}\right)$ is the eggshell conductance, $\mathrm{M}_{\mathrm{H} 2 \mathrm{O}}$ is the mass of water that was lost after $24 \mathrm{~h}$ in the desiccator $\left(\mathrm{mg}\right.$ day $\left.^{-1}\right)$, and $\Delta \mathrm{P}_{\mathrm{H} 2 \mathrm{O}}\left(\right.$ torr $\left.^{-1}\right)$ is the difference in vapor pressure between inside the egg and the outside environment (for this region, it was 23.77 torr $^{-1}$ ).

To determine the conductance, the first weight loss of the microtubes was disregarded and its measure was used for the standardization of water loss and verification of the method used. The mean between the second and third weight loss measurements was used. The mean eggshell conductance was the mean of the conductance in all regions of the eggs. The shell fragments of these eggs were also used to determine the shell porosity and thickness.

The eggshell thickness was measured using the STARRETT series 3732 external electronic micrometer (resolution $0.0001 \mathrm{~mm}$ ) on fragments taken from the wide end, equatorial, and narrow end regions, from which the mean thickness per egg was obtained. Two repetitions for each of the eggshell regions were used. The measurements were made after extracting the shell membranes. The mean eggshell thickness was calculated taking all three regions of the egg into consideration.

The number of pores in the shells was evaluated in all three regions of the eggshell. The shell fragments were prepared in accordance with the technique described by Rahn et al. (1981). Two shell fragments from each eggshell region were used. They were placed in beakers separately and boiled in $5 \%$ aqueous $\mathrm{NaOH}$ solution for 10 min. Subsequently, they were immersed in water in another receptacle and were then left to dry at room temperature for $3 \mathrm{~h}$. After they had dried, the samples were stained with an aqueous solution of $1 \%$ methylene blue, by means of a dropper, for $2 \mathrm{~min}$. They were then washed in running water and dried at room temperature for a further hour. An area of $1 \mathrm{~cm}^{2}$ divided into four areas of $25 \mathrm{~mm}^{2}$ was then marked out on each fragment, using a template. The number of pores was counted under a stereomicroscope and the sum of the four areas of $25 \mathrm{~mm}^{2}$ was considered as the number of pores per $\mathrm{cm}^{2}$ for each of the regions (large end, equator, and narrow end). The mean porosity of the eggshell was obtained as the mean of the porosities of the three eggshell regions.

All the analysis data were evaluated for normality by the Shapiro-Wilk test. After that, the data normal distribution quantitative results were subjected to analysis of variance and the means were compared by Tukey's test $(5 \%)$. Pearson's correlation $(5 \%)$ was used on the total conductance data of the eggshell in relation to various incubation and physical quality parameters from the neonates: egg weight loss from the start of incubation to the time of transfer (18 days), neonate chick weight, percentage of the neonate chick weight in relation to the egg weight, weight of the residual yolk, and net weight of the neonate chick (chick weight after subtracting the

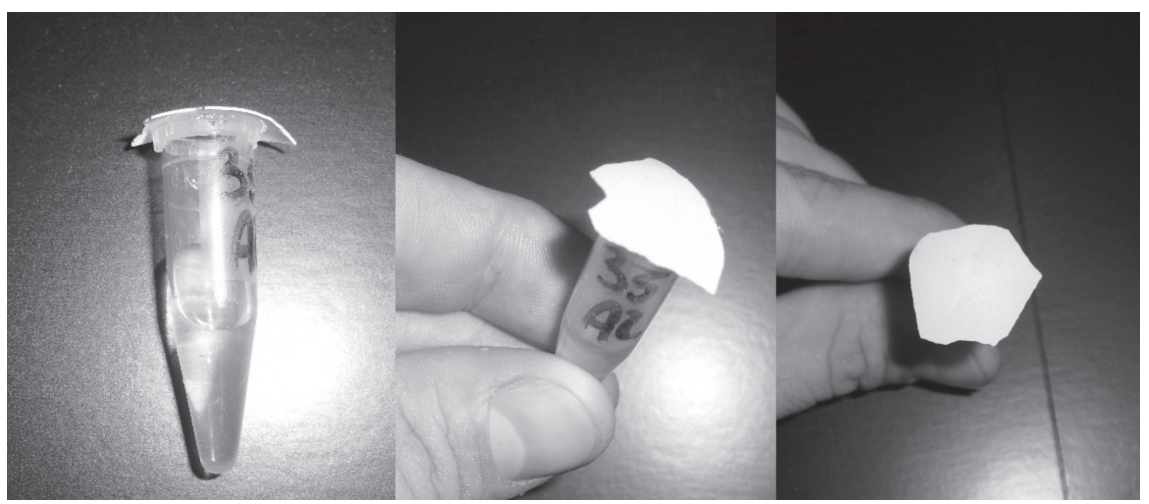

Figure 1 - Plastic microtube $(1.5 \mathrm{~mL})$ containing $1 \mathrm{~mL}$ of distilled water, with the eggshell fragment $\left( \pm 2.0 \mathrm{~cm}^{2}\right)$ glued across the opening. 
residual yolk weight). Pearson's correlation was also used among the eggshell conductance, porosity, and thickness values. All the analyses were performed using the $\mathrm{R}$ software (R Development Core Team, 2014).

\section{Results}

The factors of egg region and breeder age did not show any interaction $(\mathrm{P}>0.05)$ in relation to conductance or porosity, but there was an interaction in relation to eggshell thickness (Table 1). The mean eggshell conductance differed according to age of breeders $(\mathrm{P}<0.05)$, such that the oldest breeders (59 weeks old) presented higher eggshell conductance than the youngest breeders (29 weeks old). However, the conductance found in eggs from the oldest and youngest breeders did not differ from the conductance of eggs from breeders aged 45 weeks.

The eggshell conductance was influenced by the region of eggshell that was studied $(\mathrm{P}<0.05)$. The narrow end presented lower conductance than the other regions of the eggshell. A smaller number of pores and greater shell thickness in this region were also observed in this study $(\mathrm{P}<0.05)$. These results provide an explanation of why the specific conductance is so low in the region of the narrow end.

Eggshell thickness was influenced by age of breeders $(\mathrm{P}<0.05)$, e.g., the mean shell thickness was less in the eggs from breeders aged 59 weeks than at the other ages studied. Furthermore, the eggshell thickness was different in each eggshell region $(\mathrm{P}<0.05)$ : it was greatest at the narrow end, followed by the equator and the large end, thus showing

Table 1 - Eggshell conductance, porosity, and thickness of eggs from broiler breeders of different ages, evaluated in three different regions of the eggshell

\begin{tabular}{|c|c|c|c|}
\hline & $\begin{array}{c}\text { Eggshell } \\
\text { conductance } \\
\left(\mathrm{mg} \mathrm{day}^{-1} \text { torr }^{-1}\right)\end{array}$ & $\begin{array}{l}\text { Thickness } \\
\text { (mm) }\end{array}$ & $\begin{array}{c}\text { Porosity } \\
(\text { no. of } \\
\left.\text { pores } / \mathrm{cm}^{2}\right)\end{array}$ \\
\hline \multicolumn{4}{|c|}{ Age of breeder (weeks) } \\
\hline 29 & $0.2703 \pm 0.37 \mathrm{~b}$ & $0.3231 \pm 0.17 \mathrm{a}$ & $100 \pm 1.02$ \\
\hline 35 & $0.2855 \pm 0.53 \mathrm{ab}$ & $0.3193 \pm 0.23 \mathrm{a}$ & $104 \pm 2.05$ \\
\hline 59 & $0.3230 \pm 0.77 \mathrm{a}$ & $0.3085 \pm 0.33 b$ & $127 \pm 4.00$ \\
\hline \multicolumn{4}{|l|}{ Eggshell region } \\
\hline Large end & $0.4344 \pm 0.77 \mathrm{a}$ & $0.3084 \pm 0.77 \mathrm{c}$ & $125 \pm 0.77$ \\
\hline Equator & $0.4221 \pm 0.77 \mathrm{a}$ & $0.3184 \pm 0.77 b$ & $112 \pm 0.77$ \\
\hline Narrow end & $0.0249 \pm 0.77 \mathrm{~b}$ & $0.3233 \pm 0.77 \mathrm{a}$ & $95 \pm 0.77$ \\
\hline \multicolumn{4}{|l|}{ P-value } \\
\hline Age & $0.0008 *$ & $<0.0001 *$ & $<0.0001 *$ \\
\hline Eggshell region & $<0.0001 *$ & $<0.0001 *$ & $<0.0001 *$ \\
\hline Age $\times$ region & 0.1202 & 0.5700 & $<0.0001^{*}$ \\
\hline CV $(\%)$ & 25.2 & 7.64 & 3.68 \\
\hline
\end{tabular}

$\mathrm{CV}$ - coefficient of variation.

* Means with different letters in the same column are different according to Tukey's test $(\mathrm{P}<0.05)$ that the region of the air chamber presents the smallest thickness, which facilitates the exit of chick from the egg.

It was observed that, independent of the age of breeders, the region of the large end presented the greatest number of pores, followed by the equator and narrow end $(\mathrm{P}<0.05)$ (Table 2). In relation to age, the large end and equator regions presented significant increases in the numbers of pores $(\mathrm{P}<0.05)$ as breeders become older. However, the region of the narrow end only presented a greater number of pores at breeder ages greater than 35 weeks. Therefore, the greater conductance seen in breeders aged 59 weeks, in relation to those aged 29 weeks, was coherent with the greater porosity observed in eggs from older breeders. It could also be seen that for all eggshell regions, the number of pores was always greater $(\mathrm{P}<0.05)$ in eggs from older breeders $(59$ weeks $)$.

For Pearson's correlation analyses, strong correlations were taken to be those with $r \geq 0$. 7; moderate correlations, $r$ between 0.5 and 0.69 ; and weak correlations, $r \leq 0.49$.

Eggshell conductance did not show any significant correlation $(\mathrm{P}>0.05)$ with either thickness or porosity in the region of the large end of the egg. There was a significant correlation $(\mathrm{P}<0.05)$ between shell conductance and the number of pores both at the equator and at the narrow end of the egg (Table 3). Nevertheless, although positive, the correlations were weak.

The mean eggshell conductance was correlated $(\mathrm{P}<0.05)$ only with the chick body weight $(\mathrm{r}=0.15)$ and the yolk free chick body weight $(r=0.19)$ (Table 4$)$. The

Table 2 - Interaction between eggshell region and broiler breeder age regarding eggshell porosity (number of pores $/ \mathrm{cm}^{2}$ )

\begin{tabular}{lccc}
\hline \multirow{2}{*}{ Shell region } & \multicolumn{3}{c}{ Age of breeder (weeks) } \\
\cline { 2 - 4 } & 29 & 35 & 59 \\
\hline Large end & $110 \mathrm{Ac}$ & $113 \mathrm{Ab}$ & $148 \mathrm{Aa}$ \\
Equator & $101 \mathrm{Bc}$ & $104 \mathrm{Bb}$ & $126 \mathrm{Ba}$ \\
Narrow end & $90 \mathrm{Cb}$ & $90 \mathrm{Cb}$ & $103 \mathrm{Ca}$ \\
\hline
\end{tabular}

Means with different lowercase letters in the same line and uppercase letters in the columns are different according to Tukey's test $(\mathrm{P}<0.05)$.

Table 3 - Pearson's correlation between eggshell conductance and shell quality parameters in different regions of the egg

\begin{tabular}{lcc}
\hline & \multicolumn{2}{c}{ Egg region } \\
\cline { 2 - 3 } Conductance: eggshell quality & r & P-value \\
\cline { 2 - 3 } & \multicolumn{2}{c}{ Large end } \\
Thickness (mm) & 0.010 & 0.8876 \\
Porosity (no. of pores $\left./ \mathrm{cm}^{2}\right)$ & 0.104 & 0.1563 \\
& \multicolumn{2}{c}{ Equator } \\
Thickness (mm) & 0.058 & 0.4560 \\
Porosity (no. of pores $\left./ \mathrm{cm}^{2}\right)$ & 0.291 & $<0.0139 *$ \\
& \multicolumn{2}{c}{ Narrow end } \\
Thickness (mm) & 0.073 & 0.8200 \\
Porosity (no. of pores $\left./ \mathrm{cm}^{2}\right)$ & 0.153 & $0.0373 *$ \\
\hline
\end{tabular}

* Presents significant Pearson's correlation $(\mathrm{P}<0.05)$. 
correlations obtained for mean conductance were also all considered weak $(r \leq 0.49)$. However, according to Sampaio (2007), even a weak correlation may be an indication of a possible association between two variables.

The mean eggshell thickness did not show any correlation with any of the incubation parameters analyzed $(\mathrm{P}>0.05)$. This result emphasizes that the thickness analysis may have been impaired through the eggshell calcium intake that takes place during embryo development. Embryos take the calcium that they use for their bone formation from the internal layers of the eggshell. This attrition has a direct influence on shell thickness.

Mean eggshell porosity showed the best correlations with the incubation data. It showed weak positive correlations with egg weight loss between the start of incubation and the time of transfer (18 days) and with the yolk weight $(r \leq 0.49)$. It showed weak negative correlations with the percentage of chicken body weight and with the percentage of yolk free body weight $(r \leq 0.49)$. There was a strong positive correlation between eggshell porosity and chick body weight.

\section{Discussion}

In this study, it was shown that age affects the conductance of eggshell and the eggshell porosity is the eggshell characteristic most correlated with the incubation results. To best of our knowledge, this is the first study demonstrating this relation and the first to standardize the technique that uses eggshell fragments to quantify the conductance of eggshell of domestic chicken of different ages.

The narrow end presented lower conductance than the other regions of the eggshell. A smaller number of pores and greater shell thickness in this region were also observed in this study. Age of breeders affected the mean eggshell conductance $(\mathrm{P}<0.05)$, such that the oldest breeders (59 weeks) presented higher eggshell conductance than the youngest breeders (29 weeks). These results corroborate those of O'dea et al. (2004), who studied eggshell conductance among flocks of three different ages (37, 45, and 53 weeks), using the technique in which the whole egg was placed in the desiccator. They found that the percentage egg weight loss and eggshell conductance increased with increasing age of the hen.

These results also corroborate those of Morita et al. (2009), who studied the conductance of fertile eggs from breeders of different ages by means of egg weight loss during the first week of incubation. They found that eggs from older breeders presented higher conductance. Thus, it can be suggested that a technique using eggshell fragments might be efficient in determining eggshell conductance. According to Meir and $\operatorname{Ar}$ (2008), as age increases, eggshell conductance also increases as a consequence of the increasing numbers of pores in the eggshell and the cracks that may appear in the eggs of older breeders. These authors studied shell conductance of a batch of young breeders, starting at the age of 30 weeks. They found that water loss from the eggs at the end of the 70 weeks of age increased by $5 \%$.

The mean shell thickness was lower in eggs from old breeders. Furthermore, the eggshell thickness was different in each eggshell region, i.e., it was greatest at the narrow end, followed by the the equator and the large end, thus showing that the region of the air chamber presents the smallest thickness, which facilitates the exit of chick from the egg. These results are concordant with those of Barbosa et al. (2012), Morita et al. (2010), and Gualhanone et al. (2012), who studied the shell thickness of recently hatched eggs from broiler breeders of different ages.

Older breeders produce larger follicles, thus increasing the yolk size, which consequently increases the size of the eggs. However, the amount of calcium carbonate available to form the shell remains the same; thus, the eggshell

Table 4 - Correlation coefficient ( $\mathrm{r}$ ) and probability $(\mathrm{P})$ for mean eggshell conductance, thickness, and porosity in relation to the incubation parameters analyzed

\begin{tabular}{|c|c|c|c|c|c|c|}
\hline \multirow{2}{*}{ Parameter } & \multicolumn{2}{|c|}{ Conductance $\left(\mathrm{mg}\right.$ day $\left.^{-1} \operatorname{torr}^{-1}\right)$} & \multicolumn{2}{|c|}{ Thickness (mm) } & \multicolumn{2}{|c|}{ Porosity (no. of pores $/ \mathrm{cm}^{2}$ ) } \\
\hline & $\mathrm{r}$ & P-value & $\mathrm{r}$ & P-value & $\mathrm{r}$ & P-value \\
\hline EWL & 0.047 & 0.519 & 0.013 & 0.859 & 0.311 & $<0.001 *$ \\
\hline $\mathrm{HCW}$ & 0.158 & $<0.001 *$ & 0.065 & 0.124 & 0.870 & $<0.001^{*}$ \\
\hline HCW:IEW & 0.024 & 0.739 & -0.179 & 0.313 & -0.255 & $<0.001^{*}$ \\
\hline RYW (g) & 0.100 & 0.163 & 0.072 & 0.9216 & 0.398 & $<0.001 *$ \\
\hline RYW:HCW & 0.047 & 0.511 & -0.007 & 0.3448 & 0.142 & 0.061 \\
\hline NCW (g) & 0.194 & $<0.001 *$ & 0.100 & 0.210 & 0.853 & $<0.001^{*}$ \\
\hline NCW:HCW & -0.061 & 0.391 & -0.047 & 0.299 & -0.163 & $0.032 *$ \\
\hline
\end{tabular}

EWL - egg weight loss from start of incubation to time of transfer; HCW - hatched chick weight; HCW:IEW - ratio of hatched chick weight in relation to incubated egg weight; RYW - residual yolk weight; RYW:HCW - ratio of residual yolk weight in relation to hatched chick weight; NCW - net chick weight; NCW:HCW - ratio of net chick weight in relation to hatched chick weight.

* Presents significant Pearson's correlation $(\mathrm{P}<0.05)$ 
becomes thinner and presents a higher number of pores in eggs of older breeders (Stringhini et al., 2011). In this way, eggs from older breeders may be less resistant and may present a higher probability of defects that impair the peel quality parameters due to their smaller thickness and pore number and size.

According to Ancel and Girard (1992), eggshell porosity decreased from the large to the narrow end. The greater concentration of pores in the large end of the egg can be explained biologically. Bamelis et al. (2008) stated that the region of the air chamber is usually saturated with water vapor, which means that the gas exchange rate depends on the shell conductance, which in turn depends on shell porosity and thickness, along with the temperature and humidity of the incubator.

Higher conductance enables greater gas exchange, which may contribute to improving the use of nutritional support that is provided by the egg, thus resulting in better chick weight at birth. According to Araújo et al. (2016), eggshell conductance is related to loss of metabolic water and gases from inside the egg to the external environment. During the incubation period, it is important to maintain the rate of water loss at an appropriate level for satisfactory hatching, i.e., between 10 and 14\%. In addition, Moran $\mathrm{Jr}$ (2007) stated that metabolism of embryos during the initial period of development is practically all anaerobic. The albumen is a dominant factor in the success of the transition of the embryo from anaerobic to aerobic metabolism (Oviedo-Rondón and Murakami, 1998). Thus, around the fifth day of development, a vascular system is established, with formation of a chorioallantoic membrane capable of ensuring exchange of carbon dioxide for oxygen. Fatty acids form the main source of energy for the embryo at this stage (Sato et al., 2006).

The correlation between the conductance and eggshell and its thickness was non-existent. These results are concordant with the theory that porosity is a determinant for water loss from the egg (Meir and Ar, 2008). Thus, it can be inferred that eggshell conductance does not depend only on shell thickness. The main factor may be the number of pores present in the eggshell. Considering that eggshell thickness was measured after the incubation process, the correlation between thickness and conductance may have been impaired. According to Gualhanone et al. (2012), eggshell thickness may diminish by around $12.5 \%$ between the start of egg incubation and the day of hatching, with variations in this decrease in thickness among the different regions of the eggshell.

It was found that the greater the number of eggshell pores, the higher the chick weight. This result may be related to the age of breeder, which was seen to be directly related to the number of eggshell pores. Older breeders laid eggs with thinner and more porous shells and produced chicks of greater weight (Araújo et al., 2016). The strong positive correlations that chick weight and yolk free body weight showed in relation to mean eggshell porosity can be explained by the metabolism of the embryo, since it receives oxygen by means of diffusion through the shell pores. This observation is the basis of the biological concept of shell conductance, which may determine the quantity of energy for the embryo, the final maturation of the tissues, and the start of hatching (Christensen et al., 2006). This amount of energy may be the reason why chicks from eggs with greater conductance are heavier than those from eggs with lower conductance.

According to Oviedo-Rondón and Murakami (1998), eggshell conductance is also determined by the weight of the incubated egg, which is directly proportional to conductance. Larger eggs may have greater loss of water vapor, thereby leading to successful embryo development. Thus, according to Shafey (2002), the shells of these larger eggs are more porous and thinner, which enables greater passage of metabolic water and gases. Furthermore, for every gram of fat metabolized by the embryo, $1 \mathrm{~g}$ of metabolic water is formed and needs to be eliminated from inside the egg (Oviedo-Rondón and Murakami, 1998). This elimination is facilitated by the elevated shell porosity of eggs of greater weight and size.

Through the results from these correlations, it could be seen that eggshell porosity was fundamental for the egg to lose water. Besides, eggs with greater porosity that enabled greater gas exchange gave rise to better results. These results allow estimation of chick performance in the field, from the initial weight of the bird.

\section{Conclusions}

The technique of using eggshell fragments to determine conductance follows the same pattern as previously found in techniques that use whole eggs. There is greater conductance in eggs from older breeders. Correlation between eggshell conductance and porosity is observed. For studies on recently hatched eggs, eggshell porosity data should be used for correlations with incubation characteristics.

\section{Acknowledgments}

We thank the São Salvador Alimentos, for their support in conducting the research, and the Conselho Nacional de 
Desenvolvimento Científico e Tecnológico (CNPq), for the opportunity of the academic master's scholarship granted to the first author.

\section{References}

Ancel, A. and Girard, H. 1992. Eggshell of the domestic guinea fowl. British Poultry Science 33:993-1001.

Ar, A.; Paganelli, I. C. V.; Reeves, R. B.; Greene, D. G. and Rahn, H. 1974. The avian egg: water vapor conductance, shell thickness, and functional pore area. Condor 76:153-158.

Araújo, I. C. S.; Leandro, N. S. M.; Mesquita, M. A.; Carvalho, H. H. C.; Café, M. B. and Gonzales, E. 2016. Effect of incubator type and broiler breeder age on hatchability and broiler chick quality. Brazilian Journal Poultry Science 18(spe.2):17-25.

Bamelis, F. R.; De Ketelaere, B.; Mertens, K. and Kemps, B. J. 2008. Measuring the conductance of eggshells using the acoustic resonance technique and optical transmission spectra. Computer Electronic Agriculture 62:35-40.

Barbosa, V. M.; Baião, N. C.; Mendes, P. M. M.; Rocha, J. S. R.; Pompeus, M. A.; Lara, L. J. C. and Martins, N. R. S. 2012. Avaliação da qualidade da casca dos ovos provenientes de matrizes pesadas com diferentes idades. Arquivo Brasileiro de Medicina Veterinária e Zootecnia 64:1036-1044.

Christensen, M. J.; Ort, D. T.; Mann, K. M. and Neely, E. R. 2006. Eggshell conductance and incubator humidity as factors in embryo survival and poultry growth. International Journal Poultry Science 5:830-837.

Gonzales, E. and Mello, H. H. C. 2012. O ovo e a água. p.187-189. In: Água na avicultura industrial. 2.ed. Macari, M. and Soares, N. M., eds. FACTA, Campinas.

Gualhanone, A.; Furlan, R. L.; Fernandez-Alarcon, M. F. and Macari, M. 2012. Effect of breeder age on eggshell thickness, surface temperature, hatchability and chick weigh. Brazilian Journal Poultry Science 14:09-14.

Meir, M. and Ar, A. 2008. Changes in eggshell conductance, water loss and hatchability of layer hens with flock age and moulting. British Poultry Science 49:677-684.

Moran Jr, E. T. 2007. Nutrition of the developing embryo and hatchling. Poultry Science 86:1043-1049.
Morita, V. S.; Boleli, I. C. and Cargnelluti Filho, A. 2009. Hematological values and body, heart and liver weights of male and female broiler embryos of young and old breeder eggs. Brazilian Journal Poultry Science 11:823-845.

Morita, V. S.; Boleli, I. C. and Oliveira, J. A. 2010. Hematological and incubation parameters of chicks from young breeders eggs: Variation with sex and incubation temperature. International Journal Poultry Science 9:606-612.

O'dea E. E. O.; Fasenko, G. M.; Feddes, J. J. R.; Robinson, F. E.; Segura, J. C.; Ouellette, C. A. and Van Middelkoop, J. H. 2004. Investigating the eggshell conductance and embryonic metabolism of modern and unselected domestic avian genetic strains at two flock ages. Poultry Science 83:2059-2070.

Oviedo-Rondón, E. O. and Murakami A. E. 1998. Fatores que interferem no desenvolvimento embrionário e seus efeitos nos problemas metabólicos pós- eclosão em frangos de corte. Acta Scientarium 10:373-382.

Portugal, S. J.; Maurer, G. and Cassey, P. 2010. Eggshell permeability: a standard technique for determining interspecific rates of water vapor conductance. Physiology Biochemical Zoology 83:1023-1031.

R Development Core Team. 2011. R: A language and environment for statistical computing. R Foundation for Statistical Computing, Vienna, Austria.

Rahn, H.; Christensen, V. L. and Edens, F. W. 1981. Changes in shell conductance, pores, and physical dimensions of egg and shell during the first breeding cycle of turkey hens. Poultry Science 60:2536-2541

Sampaio I. B. M. 2007, Estatística aplicada à experimentação animal. 3.ed. FEP-MZV, Belo Horizonte.

Sato, M.; Tachibana, T. and Furuse, M. 2006. Heat production and lipid metabolism in broiler and layer chickens during embryonic development. Computer Biochemical Physiology 143:382-388

Shafey, T. M. 2002. Effects of egg size and eggshell conductance on hatchability traits of meat and layer breeder flocks. AsianAustralasian Journal Animal Sciences 15:1-6.

Stringhini, J. H.; Rocha, F. R. T.; Mello, H. H. C.; Carvalho, F. B. and Santos, B. M. 2011. Aspectos sobre a nutrição de poedeiras criadas até idades mais avançadas. p.11-15. In: Anais do $10^{\circ}$ Simpósio Goiano de Avicultura, Caldas Novas. AGA, Caldas Novas. 